\title{
Dissociation of Some Substituted Phenols in 50-Percent Aqueous Methanol as Solvent
}

\author{
R. A. Robinson and Roger G. Bates \\ Institute for Materials Research, National Bureau of Standards, Washington, D.C., 20234
}

(June 7, 1966)

\begin{abstract}
The dissociation constants of the following substituted phenols in 50 wt percent methanol have been measured at $25{ }^{\circ} \mathrm{C}$ : $o$-nitrophenol, $p$-nitrophenol, 4-methyl-2-nitrophenol, 2,6-dichlorophenol, pentachlorophenol. The respective values found, expressed as $p K$ values, are $7.91_{7}, 7.69_{2}, 8.28_{4}$, $7.68_{0}$, and $5.27_{8}$. The dissociation constants of 4-methyl-2-nitrophenol and pentachlorophenol, again expressed as $p K$ values, have been measured in water as solvent at $25^{\circ} \mathrm{C}$ and found to be $7.59_{7}$ and $4.82_{0}$, respectively.
\end{abstract}

Key Words: Dissociation constant, methanol-water mixtures, solvent effects, substituted phenols.

\section{Introduction}

The dissociation constants of protonated tris(hydroxymethyl) aminomethane [1] ${ }^{1}$ and of the ammonium ion in $50 \mathrm{wt}$ percent aqueous methanol [2] have been determined recently over the temperature range 10 to $40{ }^{\circ} \mathrm{C}$. The dissociation constants of acetic acid and of the dihydrogen phosphate ion have also been determined [3] over this temperature range. The emf measurements needed to evaluate the dissociation constants of acetic acid and dihydrogen phosphate ion also yielded values of the acidity function $p\left(a_{\mathrm{H}} \gamma_{\mathrm{Cl}}\right)$ $\cong-\log \left(a_{\mathrm{H}^{+}} \cdot \gamma_{\mathrm{Cl}^{-}}\right)$for a buffer solution containing equimolar acetic acid, sodium acetate, and sodium chloride (Solution A) and another buffer solution containing equimolar potassium dihydrogen phosphate, disodium hydrogen phosphate, and sodium chloride (Solution B) in 50 percent methanol. The $p\left(a_{\mathrm{H}} \gamma_{\mathrm{Cl}}\right)$ value of Solution A is approximately 5.7, that of Solution B 8.2, the exact value depending on the temperature and the total ionic strength of the solution.

Advantage has now been taken of these buffer solutions to determine the dissociation constants of the following substituted phenols in 50 percent methanol at $25{ }^{\circ} \mathrm{C}$ : $o$-nitrophenol, $p$-nitrophenol, 4-methyl-2-nitrophenol, 2,6-dichlorophenol, and pentachlorophenol. The order of magnitude of the $p K$

${ }^{1}$ Figures in brackets indicate the literature references at the end of this paper. values of these phenols is such that either Solution A or Solution B is a suitable buffer solution for spectrophotometric measurements of the dissociation constants. Comparison with the $p K$ values in aqueous solution can be made because such $p K$ values have already been determined for the following; $o$-nitrophenol [4], p-nitrophenol [5], and 2,6-dichlorophenol [6]. In order to complete the series, the dissociation constants of 4-methyl-2-nitrophenol and of pentachlorophenol have now been measured in aqueous solution at $25^{\circ} \mathrm{C}$.

\section{Outline of Method}

In the spectrophotometric method the optical densities of three solutions of the phenol are measured. One contains sufficient acid to convert the phenol entirely into its undissociated form, HN; the optical density is denoted by $D_{1}$. The second solution contains sufficient alkali to convert the phenol entirely into its anion, $\mathrm{N}^{-}$, the optical density of this solution being $D_{2}$. The third solution, of optical density $D$, contains a buffer solution whose $p\left(a_{\mathrm{H}} \gamma_{\mathrm{Cl}}\right)$ value is known. It is an advantage if a series of such buffer solutions of different total ionic strengths are available. The stoichiometric concentration of phenol in each solution is the same. Measurements of optical density are made at a wavelength where $D_{2}$ is large and $D_{1}$ small. 
The fraction, $\alpha$, of the phenol present in the anionic form in the third solution is given by

$$
\alpha=\frac{D-D_{1}}{D_{2}-D_{1}}
$$

The dissociation constant of the phenol is defined as:

$$
K=\frac{a_{\mathrm{H}^{+}} \cdot m_{\mathrm{N}^{-}}}{m_{\mathrm{HN}}} \cdot \frac{\gamma_{\mathrm{N}^{-}}}{\gamma_{\mathrm{HN}}}
$$

whence

$$
p K=p\left(a_{\mathrm{H}} \gamma_{\mathrm{Cl}}\right)-\log \frac{D-D_{1}}{D_{2}-D}-\log \frac{\gamma_{\mathrm{N}^{-}}}{\left(\gamma_{\mathrm{Cl}^{-}} \cdot \gamma_{\mathrm{HN}}\right)} .
$$

The last term in eq (3) is either negligible or small; in the latter case, the true value of $p K$ can be obtained by extrapolation to zero total ionic strength. A small correction is needed because the $p\left(a_{\mathrm{H}} \gamma_{\mathrm{Cl}}\right)$ value of the buffer solution is changed slightly on addition of the phenol; this correction has already been considered [7].

\section{Materials}

$o$-Nitrophenol, p-nitrophenol, and 2,6-dichlorophenol were available from previous work $[4,5,6]$. 4-Methyl2-nitrophenol was twice recrystallized from a mixture of petroleum ether and heptane; $\mathrm{mp} 32{ }^{\circ} \mathrm{C}$. It has absorption maxima in aqueous alkali solution at 433 $\mathrm{m} \mu\left(\epsilon_{2} 4,480\right)$ and $368 \mathrm{~m} \mu\left(\epsilon_{1} 2,880\right)$ in acid solution with an isosbestic point at $388 \mathrm{~m} \mu(\epsilon 2,380)$. Pentachlorophenol was recrystallized twice from a mixture of water and methanol; mp $193{ }^{\circ} \mathrm{C}$. In aqueous solution the spectrum exhibits maxima at $320 \mathrm{~m} \mu\left(\epsilon_{2} 4,870\right)$ in alkali solution and at $302 \mathrm{~m} \mu\left(\epsilon_{1} 2,000\right)$ in acid solution; it has no isosbestic point in this region of the spectrum.

\section{Spectrophotometric Measurements}

The details of the measurements are given in tables 1 through 7 . For the determination of the $p K$ value of 4-methyl-2-nitrophenol in aqueous solution both tris(hydroxymethyl)aminomethane and phosphate buffer solutions were used; $p\left(a_{\mathrm{H}} \gamma_{\mathrm{Cl}}\right)$ values for these buffer solutions have been tabulated [8]. The equimolal sodium hydrogen succinate-sodium chloride buffer solutions proved satisfactory for measuring the $p K$ value of pentachlorophenol; $p\left(a_{\mathrm{H}} \gamma_{\mathrm{Cl}}\right)$ values for these buffer solutions have also been tabulated [8]. The acidity functions $p\left(a_{\mathrm{H}} \gamma_{\mathrm{Cl}}\right)$ listed in tables 1 through 7 for both solvent media relate to the buffer mixtures without added phenol. A correction for the change in acidity produced by the phenol is, however, included in the values of $p K^{\prime}$ (corr) given in the last column of each of these tables.
TABLE 1. Dissociation constant of 4-methyl-2-nitrophenol in aqueous solution at $25^{\circ} \mathrm{C}$

Phenol concentration $1.83 \times 10^{-4} \mathrm{M}$, cell length $1 \mathrm{~cm}$, wavelength $433 \mathrm{~m} \mu, D_{1} 0.075, D_{2} 0.819$

\begin{tabular}{r|r|r|r|r|r}
\hline$l$ & $p\left(a_{\mathrm{H}} \gamma_{\mathrm{Cl}}\right)$ & \multicolumn{1}{l|}{$D$} & $\log \frac{D-D_{1}}{D_{2}-D}$ & $p K$ & $p K($ corr $)$ \\
\hline 0.01 & 8.176 & 0.660 & 0.566 & 7.610 & 7.598 \\
.02 & 8.207 & .669 & .598 & 7.609 & 7.603 \\
.03 & 8.232 & .675 & .620 & 7.612 & 7.608 \\
.04 & 8.251 & .685 & .658 & 7.593 & 7.590 \\
.05 & 8.266 & .684 & .653 & 7.613 & 7.611 \\
.06 & 8.280 & .690 & .678 & 7.602 & 7.600 \\
.08 & 8.302 & .697 & .707 & 7.595 & 7.594 \\
.10 & 8.321 & .700 & .720 & 7.601 & 7.600 \\
\hline
\end{tabular}

The buffer solution contained tris(hydroxymethyl)aminomethane $(\mathrm{m})$, and its hydrochloride $(0.9843 \mathrm{~m}) . \quad I=0.9843 \mathrm{~m}$.

\begin{tabular}{|c|c|c|c|c|c|}
\hline$I$ & $p\left(a_{\mathrm{H}} \gamma_{\mathrm{Cl}}\right)$ & $D$ & $\log \frac{D-D_{1}}{D_{2}-D}$ & $p K$ & $p K($ corr $)$ \\
\hline 0.02 & 7.080 & 0.247 & -0.525 & 7.605 & 7.598 \\
\hline .04 & 7.040 & .239 & -.552 & 7.592 & 7.589 \\
\hline .05 & 7.026 & .233 & -.573 & 7.599 & 7.596 \\
\hline .06 & 7.013 & .230 & -.578 & 7.591 & 7.589 \\
\hline .08 & 6.992 & .226 & -.598 & 7.590 & 7.588 \\
\hline .10 & 6.974 & .218 & -.627 & 7.601 & 7.600 \\
\hline
\end{tabular}

Phenol concentration $1.83 \times 10^{-4} \mathrm{M}$, cell length $1 \mathrm{~cm}$, wavelength $433 \mathrm{~m} \mu, D_{1} 0.076, D_{2} 0.820$

The buffer solution contained equimolar amounts of potassium dihydrogen phosphate $(\mathrm{m})$ and disodium hydrogen phosphate $(\mathrm{m})$. $I=4 \mathrm{~m}$.

TABLE 2. Dissociation constant of pentachlorophenol in aqueous solution at $25^{\circ} \mathrm{C}$

Phenol concentration $1.69 \times 10^{-5} \mathrm{M}$, cell length $10 \mathrm{~cm}$, wavelength $320 \mathrm{~m} \mu, D_{1} 0.015, D_{2} 0.823$

\begin{tabular}{r|r|r|r|r|r}
\hline$I$ & $p\left(a_{\mathrm{H}} \gamma_{\mathrm{Cl}}\right)$ & \multicolumn{1}{c|}{$D$} & $\log \frac{D-D_{1}}{D_{2}-D}$ & $p K$ & $p K$ (corr) \\
\hline 0.040 & 4.851 & 0.435 & 0.034 & 4.817 & 4.816 \\
.064 & 4.838 & .426 & .015 & 4.823 & 4.822 \\
.096 & 4.827 & .422 & .006 & 4.821 & 4.821 \\
.144 & 4.814 & .415 & -.009 & 4.823 & 4.823 \\
.200 & 4.802 & .411 & -.017 & 4.819 & 4.819 \\
\hline
\end{tabular}

The buffer solution contained sodium hydrogen succinate $(\mathrm{m})$ and sodium chloride $(\mathrm{m}) . \quad I=2 \mathrm{~m}$.

TABLE 3. Dissociation constant of o-nitrophenol in 50 percent methanol at $25^{\circ} \mathrm{C}$

Phenol concentration $1.50 \times 10^{-4} \mathrm{M}$, cell length $1 \mathrm{~cm}$, wavelength $418 \mathrm{~m} \mu, D_{1} 0, D_{2} 0.718$

\begin{tabular}{r|r|r|r|r|r}
\hline \multicolumn{1}{r|}{$I$} & $p\left(a_{H} \gamma_{C 1}\right)$ & \multicolumn{1}{c|}{$D$} & $\log \frac{D-D_{1}}{D_{2}-D}$ & $p K^{\prime}$ & $p K^{\prime}$ (corr) \\
\hline 0.02 & 8.248 & 0.488 & 0.302 & 7.946 & 7.922 \\
.04 & 8.178 & .463 & .233 & 7.945 & 7.933 \\
.06 & 8.127 & .444 & .182 & 7.945 & 7.937 \\
.08 & 8.085 & .426 & .135 & 7.950 & 7.944 \\
.10 & 8.049 & .409 & .092 & 7.957 & 7.952 \\
\hline
\end{tabular}

The buffer solution contained potassium dihydrogen phophate $(\mathrm{m})$, disodium hydrogen phosphate $(\mathrm{m})$, and sodium chloride $(\mathrm{m}) . \quad I=5 \mathrm{~m}$. 
TABLE 4. Dissociation constant of p-nitrophenol in 50 percent methanol at $25^{\circ} \mathrm{C}$

Phenol concentration $5.18 \times 10^{-5} \mathrm{M}$, cell length $1 \mathrm{~cm}$, wavelength $402 m \mu, D_{1} 0, D_{2} 1.042$

\begin{tabular}{r|r|r|r|r|r}
\hline \multicolumn{1}{r|}{} & & & \multicolumn{1}{c|}{$\begin{array}{l}D-D_{1} \\
D_{2}-D\end{array}$} & $p K^{\prime}$ & $p K^{\prime}$ (corr) \\
\hline 0.02 & 8.248 & 0.810 & 0.543 & 7.705 & 7.697 \\
.04 & 8.178 & .773 & .458 & 7.720 & 7.716 \\
.06 & 8.127 & .743 & .396 & 7.731 & 7.728 \\
.08 & 8.085 & .722 & .353 & 7.732 & 7.730 \\
.10 & 8.049 & .698 & .307 & 7.742 & 7.740 \\
\hline
\end{tabular}

The buffer solution contained potassium dihydrogen phosphate $(\mathrm{m})$, disodium hydrogen phos phate $(\mathrm{m})$, and sodium chloride $(\mathrm{m}) . \quad I=5 \mathrm{~m}$.

TABLE. 5. Dissociation constant of 4-methyl-2-nitrophenol in 50 percent methanol at $25^{\circ} \mathrm{C}$

\begin{tabular}{|c|c|c|c|c|c|}
\hline \multicolumn{6}{|c|}{$\begin{array}{l}\text { Phenol concentration } 1.81 \times 10^{-4} \mathrm{M} \text {, cell length } 1 \mathrm{~cm} \text {, } \\
\text { wavelength } 436 \mathrm{~m} \mu, D_{1} 0.041, D_{2} 0.875\end{array}$} \\
\hline$I$ & $p\left(a_{\mathrm{H}} \gamma_{\mathrm{Cl}}\right)$ & $D$ & $\log \frac{D-D_{1}}{D_{2}-D}$ & $p K^{\prime}$ & $p K^{\prime}($ corr $)$ \\
\hline 0.02 & 8.248 & 0.431 & -0.056 & 8.304 & 8.285 \\
\hline .04 & 8.178 & .403 & -.115 & 8.293 & 8.283 \\
\hline .06 & 8.127 & .377 & -.171 & 8.298 & 8.292 \\
\hline .08 & 8.085 & .359 & -.210 & 8.295 & 8.290 \\
\hline .10 & 8.049 & .324 & -.244 & 8.293 & 8.289 \\
\hline
\end{tabular}

The buffer solution contained potassium dihydrogen phosphate $(\mathrm{m})$, disodium hydrogen phosphate $(\mathrm{m})$, and sodium chloride $(\mathrm{m}) . \quad I=5 \mathrm{~m}$.

TABLE 6. Dissociation constant of 2,6-dichlorophenol in 50 percent methanol at $25^{\circ} \mathrm{C}$

\begin{tabular}{l} 
Phenol concentration $1.55 \times 10^{-4} \mathrm{M}$, cell length $1 \mathrm{~cm}$, \\
wavelength $298 \mathrm{~m} \mu, D_{1} 0.012, D_{2} 0.971$ \\
\hline \\
\hline
\end{tabular}

The buffer solution contained potassium dihydrogen phosphate $(\mathrm{m})$, disodium hydrogen phosphate $(\mathrm{m})$, and sodium chloride $(\mathrm{m}) . \quad I=5 \mathrm{~m}$.

TABLE 7. Dissociation constant of pentachlorophenol in 50 percent methanol at $25^{\circ} \mathrm{C}$

\begin{tabular}{l}
\hline \hline \multicolumn{6}{c}{$\begin{array}{l}\text { Phenol concentration } 1.99 \times 10^{-4} \mathrm{M} \text {, cell length } 1 \mathrm{~cm}, \\
\text { wavelength } 323 \mathrm{~m} \mu, D_{1} 0.002, D_{2}\end{array} 1.013$} \\
\hline \\
\hline
\end{tabular}

The buffer solution contained acetic acid $(\mathrm{m})$, sodium acetate $(\mathrm{m})$, and sodium chloride (m). $I=2 \mathrm{~m}$.
Inspection of tables 1 and 2 shows that the $p K$ values of 4-methyl-2-nitrophenol and pentachlorophenol in aqueous solution are almost independent of the total ionic strength of the buffer solution, the difference between any one value and the mean being within the experimental error. This is in accordance with previous experience with other aqueous solutions; the mean of the recorded $p K$ values was, therefore, taken as the best value.

This does not hold for phenols in 50 percent methanol, as tables 3 through 7 show. For this reason, the quantity

$$
p\left(a_{\mathrm{H}} \gamma_{\mathrm{Cl}}\right)-\log \frac{D-D_{1}}{D_{2}-D}
$$

in tables 3 through 7 has been called $p K^{\prime}$; it is identical with $p K+\log \gamma_{\mathrm{N}}-/\left(\gamma_{\mathrm{Cl}}-\cdot \gamma_{\mathrm{HN}}\right)$. The variation of $p K^{\prime}$ is linear with total ionic strength. It is not great in the case of 4-methyl-2-nitrophenol, but it is considerable with the other four phenols; moreover, while the $p K^{\prime}$ values of four of the phenols increase with increasing ionic strength, they decrease in the case of 2,6-dichlorophenol. It is clear that the activity coefficient term in eq (3) is very specific to each phenol. For this reason, the true values of $p K$ were obtained by extrapolating $p K^{\prime}$ to zero ionic strength, using the method of least squares.

Since the data for $p\left(a_{\mathrm{H}} \gamma_{\mathrm{Cl}}\right)$ have been recorded in molality units, all $p K$ values in this paper are also on the molality scale.

\section{Results}

Table 8 gives the $p K$ values obtained in this work and values for some phenols in aqueous solutions obtained in earlier work $[4,5,6]$.

In aqueous solution the substitution of a methyl group in the para position raises the $p K$ value of $o$-nitrophenol by $0.36_{7}$. A similar substitution of a methyl group in phenol itself has been found to raise the $p K$ value by $0.26_{4}$ [9] or $0.25_{6}$ [10]. The joint effects of $p-\mathrm{CH}_{3}$ and $o-\mathrm{NO}_{2}$ are, therefore additive only to a poor approximation. The same has been shown to be true, to a greater degree [11], for 2,4dinitrophenol with $p K=4.09 \quad[12]$; here the substitution of a $p-\mathrm{NO}_{2}$ group in $o$-nitrophenol has lowered the $p K$ value by 3.14 whereas the lowering would have been 2.84 if additivity held.

The $p K$ values of $o_{-}, m$-, and $p$-chlorophenol are $8.53_{4}, 9.13_{0}$, and $9.41_{8}$, respectively [13], so that $o-$, $m-$, and $p$-Cl substitution lowers the $p K$ value of phenol by $1.46_{4}, 0.86_{8}$, and $0.58_{0}$. If the effects were additive, one would expect $p K=4.75_{4}$ for pentachlorophenol compared with the observed value of $4.82_{0}$. It has been found [6] that an additivity principle is moderately successful in accounting for the $p K$ values of the dichlorophenols, except for 2,6-dichlorophenol for which an additivity rule would predict a $p K$ value 0.27 greater than the observed. It is interesting to observe that when substitution of chlorine atoms occurs at all five possible positions in the phenol 
TABLE 8. Values of $\mathrm{pK}$ for substituted phenols in aqueous solution and in 50 percent methanol at $25^{\circ} \mathrm{C}$

\begin{tabular}{|c|c|c|c|}
\hline & Water & $\begin{array}{l}50 \text { percent } \\
\text { Methanol }\end{array}$ & $\Delta^{\mathrm{a}}$ \\
\hline 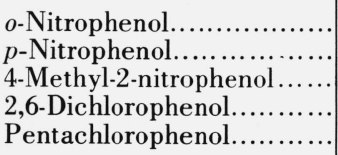 & $\begin{array}{l}7.23_{0} \\
7.15_{6} \\
7.59_{7} \\
6.79_{1} \\
4.82_{0}\end{array}$ & $\begin{array}{l}7.91_{7} \\
7.69_{2} \\
8.28_{4} \\
7.68_{0} \\
5.27_{8}\end{array}$ & $\begin{array}{r}0.68_{7} \\
.53_{6} \\
.68_{7} \\
.88_{9} \\
.45_{8}\end{array}$ \\
\hline
\end{tabular}

${ }^{\text {a }} \Delta=p K$ (in 50 percent methanol) $-p K$ (in water).

molecule, the anomaly is greatly reduced; an additivity principle, as shown above, predicts a $p K$ value within 0.07 of the observed.

The information available about the dissociation constants of weak acids in 50 percent methanol is not extensive. The dissociation constant of $p$-nitrophenol in a number of water-methanol solvents has been determined by de Ligny, Loriaux, and Ruiter [14]; interpolation at 50 percent methanol gives $p K=7.74$ compared with $7.69_{2}$ in table 8 .

Our measurements [3] of the $p K$ value of dihydrogen phosphate ion show that it is 0.245 higher in 50 percent methanol than in water (at $25^{\circ} \mathrm{C}$ ). The corresponding difference for acetic acid is 0.904, in good agreement with values interpolated from the conductance data of Shedlovsky and Kay [15] and the emf results of Bacarella, Grunwald, Marshall, and Purlee [16]. Interpolation of the data of the latter at 50 percent methanol gives the following differences between $p K$ in 50 percent methanol and $p K$ in water for formic acid, propionic acid, butyric acid, and benzoic acid, respectively, 0.70, 1.03, 1.02, and 1.18.

The medium effect, therefore, as measured by the difference in $p K$ in the two solvents, covers a wide range of values. It is difficult to see why, in a series of four aliphatic acids, the medium effect should increase with increasing size of the molecule. The Born equation or any modification of it would lead one to predict the opposite order.
The five acids listed in table 8 might be thought to resemble benzoic acid in configuration, yet the medium effect for benzoic acid $(\Delta p K=1.18)$ is considerably higher than that found for these five acids $\left(0.45_{8}-\right.$ $0.88_{9}$ ). In selecting these five phenols it was hoped that a more or less constant medium effect would be observed which could be taken as characteristic of phenolic acids. It may be disappointing to find that this is not so, but it is useful to realize now that the problem is complicated and that apparently minor changes in structure can lead to differences in the medium effect.

\section{References}

[1] M. Woodhead, M. Paabo, R. A. Robinson, and R. (;. Bates, J. Res. NBS 69A (Phys. and Chem.) No. 3, 263 (1965).

[2] M. Paabo, R. (;. Bates, and R. A. Robinson, J. Phys. Chem. 70, 247 (1966).

[3] M. Paabo, R. A. Robinson, and R. G. Bates, J. Am. Chem. Soc. 87, 415 (1965).

[4] R. A. Robinson and A. Peiperl, J. Phys. Chem. 67, 1723 (1963).

[5] G. F. Allen, R. A. Robinson, and V. E. Bower, J. Phys. Chem. 66, 171 (1962).

[6] K. A. Robinson, J. Res. NBS 68A (Phys. and Chem.) No. 2, 159 (1964).

[7] R. A. Robinson and A. K. Kiang, Trans. Faraday Soc. 51, 1398 (1955).

[8] R. G. Bates and R. Gary, J. Res. NBS 65A (Phys. and Chem.) No. 6, 495 (1961).

[9] A. I. Biggs, Trans. Faraday Soc. 52, 35 (1956).

[10] D. T. Y. Chen and K. J. Laidler, Trans. Faraday Soc, 58, 480 (1962).

[11] R. A. Robinson, M. M. Davis, M. Paabo, and V. E. Bower, J. Res. NBS 64A (Phys. and Chem.) No. 4, 347 (1960).

[12] H. von Halban and G. Kortüm, Z. Physik. Chem. A170, 351 (1934).

[13] A. I. Biggs, J. Chem. Soc. (London) 388 (1961).

[14] C. L. de Ligny, H. Loriaux, and A. Ruiter, Rec. Trav. Chim. 80, 725 (1961).

[15] T. Shedlovsky and R. L. Kay, J. Phys. Chem. 60, 151 (1956).

[16] A. L. Bacarella, E. Grunwald, H. P. Marshall, and E. L. Purlee, J. Org. Chem. 20, 747 (1955).

(Paper 70A6-427) 